\title{
A preliminary analysis of gender violence among migrants and displaced people in Europe
}

\section{DOI: http://doi.org/10.26758/8.1.5}

Santiago Boira (1), Anita Nudelman (2), Tina (Tiko) Tsomaia (3)

(1) University of Zaragoza, Spain

(2) Ben Gurion University, Israel

(3) Georgian Institute of Public Affairs (GIPA), Tbilisi (Georgia)

Address correspondence to: Santiago Boira. Facultad de Ciencias Sociales y del Trabajo. University of Zaragoza. C/ Violante de Hungría, 23, 50009 Zaragoza (Spain). Ph.:+0034976761600; E-mail: sboira@unizar.es

\begin{abstract}
Background. The vulnerability of migrant women, especially those coming from patriarchal societies, leads to the increase of gender violence. This is incremented by a myriad of socioecological determinants related to the immigration process and to the nature of male-female relationships.

Objectives. The main objective is to conduct a preliminary analysis of recent publications dealing with the relations between gender violence and migrant populations in the European Union, including internally displaced people.

Materials and methods. This paper is based on a revision of scientific publications from SCOPUS that relate to migrant women who are victims of gender violence in the European Union. The qualitative thematic analysis was used in order to identify the main issues targeted in the articles.

Results. The thematic analysis of the studies reviewed dealing with migration and gender violence highlighted several important themes, including prevalence of violence against migrant women; the forms and contexts of gender violence; the impact of legal, economic environments and sociocultural barriers; the influence of conflict and war; the impact and consequences of violence, especially on women's mental health, as well as strategies and suggestions for interventions.

Conclusions. Increasing the awareness of migration, regarding the conflicts and problems experienced by migrants (of both genders), could enable health and legal authorities to offer more significant culture and gender sensitive services, thus reducing gender violence.
\end{abstract}

Keywords: migration; gender inequality; violence

\section{Introduction}

During the last few years, the European Union has experienced a constant population flow arriving through different entry points, sometimes after long and difficult journeys. In 2015, there were an estimated 2.7 million immigrants to the EU-28 from non-member countries. The largest total number of immigrants was in Germany, followed by the United Kingdom, France, Spain and Italy (Eurostat, 2016). Many of them came from the Middle East, Asia, Africa and America due to 
prolonged wars and political reasons, as well as economic ones. Nevertheless, it is difficult to determine when the migration process will end for these women, since it implies a vital readjustment process in the host society, which can last for many years and even a lifetime.

Gender violence against immigrant women is at epidemic proportions, but research has only recently begun to address this concern (Raj and Silverman, 2002). Various studies have indicated that migrant women are highly vulnerable to domestic violence in European host countries. The vulnerability of migrant women, especially those coming from patriarchal societies, leads to the increase of domestic violence and abuse. This is incremented by a myriad of socioecological determinants related to the immigration process and to the nature of male-female relationships.

Women's isolation due to language and cultural barriers, as well as legal ones, is often increased by socio-economical dependency on their husbands/partners, thus affecting their ability to lodge complaints (for example, go to the police), as well as their access to support networks and professional assistance (Runner, Yoshihama and Novick, 2009; Rana, 2012; Ingram, 2007).

Women who are not citizens of the country in which they reside were found to have a higher prevalence of physical and sexual violence (European Union Agency for Fundamental Rights, 2014), thus making domestic violence a major force of victimization (Davis, Erez and Avitabile, 2001; Carbajosa, et al., 2011; Hazen and Soriano, 2007; Gracia et al., 2010). It is also important to consider the suffering of some of these women in the context of other critical global issues and processes, such as trafficking of women, the effects of patriarchal culture, as well as intra and intergenerational issues.

Femicide is defined widely as the killing of women because of their gender, although it includes different types of phenomena, such as intimate partner murder and honor killings and is often explained using different models (Corradi et al., 2016). "Failed femicide" attempts (Weil, 2016a) have received little attention across Europe.

A recent study among women who survived a femicide attempt indicates some common characteristics shared by migrant women from different countries, such as having been through a process of increasing violence, the forms of violence experienced and how these affected them. In addition, aggressors were described as "control freaks", very jealous and trying to restrict women's movement and activities. In order to justify their aggression, they tend to falsely accuse their wives of being promiscuous, while children are often used to manipulate and pressure their wives. In addition, these women showed an ambivalent attitude towards security forces and care professionals due to lack of trust. Barriers to access services may also be exacerbated due to pressure from the communities of origin in the host country (Nudelman et al., 2017).

When considering migrant male abusers, Fernández-Montalvo et al. (2011) sustain that they are younger, with more children in common with the victim, with a slightly higher level of education and with a longer history of mental illness than Spanish abusers. Furthermore, migrant abusers have more irrational thoughts about women and the use of violence (Echeburúa y Fernández-Montalvo, 1998), and they have experienced childhood abuse more often than their Spanish counterparts.

The aim of this article was to conduct a preliminary analysis of recent publications dealing with the relation between gender violence and migrant populations, including internally displaced people. This is part of a larger study to assess the impact of different factors related to the migration process and the increase of gender violence, including femicide - while focusing on migrants in the European Union. 
The total number of persons born outside the EU-28 and living in an EU Member State on January 1, 2016 was estimated at 35.1 million, while an additional 19.3 million persons were born in a different EU Member State from the one where they were resident (Eurostat, 2016). When considering internally displaced people (IDPs) mostly due to conflicts, the highest number in the EU can be found in Cyprus 272,000 (IDMC, 2017).

The hypothesis suggested is that migrant women's insecure status in Europe may increase their risk of suffering from severe gender violence, making it more difficult for them to come forward, denounce their aggressors and to access the host country's services, thus decreasing their chances of leaving the cycle of violence. Thus, it is of utmost importance to increase awareness, sensitivity, and knowledge on socio-cultural perspectives which may influence gender violence among migrant women.

\section{Material and methods}

This paper is based on a preliminary revision of scientific articles that relate to the issue of migrant women who are victims of gender violence in countries of the EU. SCOPUS was selected since it is one of the most comprehensive databases, which includes the highest indexed and most representative scientific publications and was accessed in August 2017.

The following strategy was used to identify the relevant publications: the initial search limited the time frame to publications as from 2000, in order to base our analysis on the most recent ones, incorporating all the references found in the database, including research articles, systematic reviews, book chapters or any other kind of reference; the second one focused on publications with key words "migrant", " migration" or "displaced people" combined with the terms "domestic violence", "gender violence", "violence against women", "intimate partner violence" or "femicide". The final search was limited to publications referring to member countries of the European Union, as well as Israel, which is grouped together with the European region by many international agencies.

After identifying the relevant publications, a descriptive analysis was performed. Finally, the preliminary thematic analysis was made, based on the main themes identified in the abstracts.

\section{Results}

The resulting number of publications referring to migrant population or displaced people was 414 . Of these only $70(16.9 \%)$ were situated in the territory of countries of the European Union.

\section{Descriptive analysis of the publications}

In this section, the publications will be described according to the year of publication, type of journal, language and countries.

Considering the year of publication, as years go by, a growing interest in themes focusing on migration and displaced populations can be observed (Figure 1). 


\section{Figure 1. Yearly amount of publications}

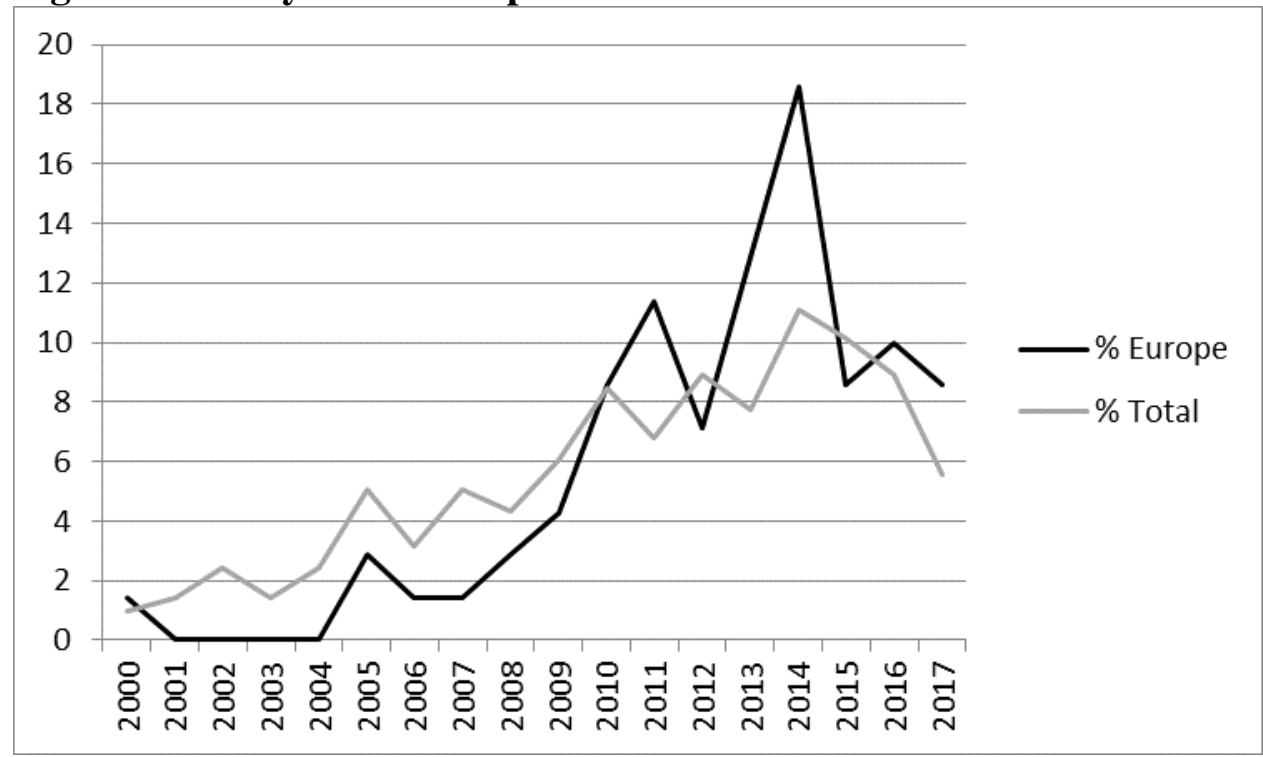

When considering the type of publications, most of them $(\mathrm{N}=62)$ are academic articles representing $89 \%$, followed by reviews $(6 \%)$.

Most of these publications are written in English (54), 12 of them in Spanish, 4 in German, two in Portuguese and one in French.

Figure 2. Publications according to disciplines

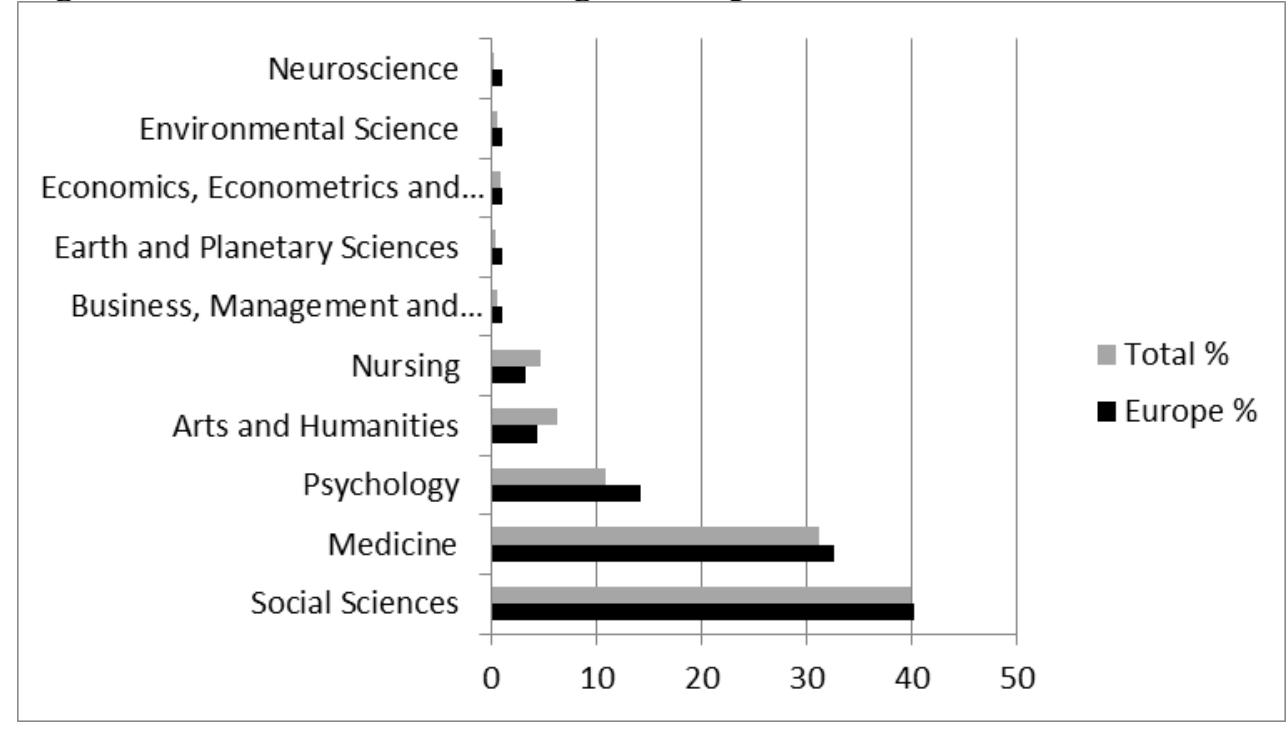


The main disciplines dealing with issues related to migration, displaced populations, and gender violence are social sciences, medicine, and psychology (Figure 3).

This distribution is similar both among studies focusing on European countries and on the rest of the world.

The countries in Europe where the research took place can be observed in Table 1.

Table 1. Distribution of publications by countries

\begin{tabular}{|l|c|}
\hline \multicolumn{1}{|c|}{ Country } & References \\
\hline Spain & 26 \\
\hline United Kingdom & 16 \\
\hline Sweden & 6 \\
\hline Germany & 5 \\
\hline Italy & 4 \\
\hline France & 2 \\
\hline Israel & 2 \\
\hline Netherlands & 2 \\
\hline Portugal & 2 \\
\hline Switzerland & 2 \\
\hline France & 2 \\
\hline Belgium & 1 \\
\hline Finland & 1 \\
\hline Ireland & 1 \\
\hline Norway & 1 \\
\hline Poland & 1 \\
\hline Romania & 1 \\
\hline
\end{tabular}

The countries from which most references were found were Spain and the United Kingdom. This is closely related to the professional affiliation of the researchers, who mostly work in Spanish and British Universities.

\section{Thematic analysis}

The main themes that emerged from the analysis of the studies focusing on gender violence and migrants in the European Union related to the increasing prevalence of violence; the forms, causes and contexts of gender violence; the impact of legal, economic environments and socio-cultural barriers; the influence of conflict and war; the impact and consequences of violence, especially on women's mental health, as well as strategies and suggestions for interventions. It is important to note that some themes overlap, thus articles may include more than one theme.

Prevalence of violence against migrant women. A group of studies relates to the prevalence of violence among migrant women (Legouge and Pfefferkorn 2011), indicating that it is still one of the most brutal manifestations of the inequalities between men and women. For 
example, in Italy prevalence of abuse is associated with domestic violence among couples in which the mothers are migrants and the fathers Italian (Cammarella et al., 2016). Similarly, violence is considered a frequent problem among both female and male immigrants living in Portugal, with different gender patterns regarding the perpetrators and settings of abuse (Dias, Fraga and Barros, 2013).

The movement towards a real equality is partial and contradictory especially in contexts where immigrants constitute a vulnerable population. Thus, violence may be both higher and underreported among immigrants (Colorado - Yohar et al., 2012).

The forms, causes, and contexts of gender violence. Considering different forms of gender violence, intimate partners committed significantly more homicide-suicides among emigrants than non-emigrants in Romania. Emigrant homicide-suicides also had significantly more reports of prior abuse than non-emigrant homicide-suicides (Balica and Stöck1, 2016).

In Israel, between 1995 and 2007, different characteristics of intimate femicide were identified. Ethiopian immigrants differed significantly from the others due to a pattern of femicide followed by suicide, while among immigrants from the former USSR femicide under the influence of alcohol was prevalent (Sela-Shayovitz, 2010).

Immigrant women also have a higher risk of suffering psychological abuse. In addition, migrant women's awareness of violence differs from native ones: while Spanish women had more difficulty recognizing psychological violence, for Romanian migrants in Spain, it was easier to identify some of the behaviors involving physical or sexual violence (Rabito-Alcón et al., 2013).

Finally, one of the studies identified targeted a specific type of femicide among migrant communities in Europe - honor killings - a culturally specific form of gender-related homicide exacerbated by the migration process. This direct violence against women can be considered a patriarchal backlash in a situation of structural changes in gender relations (Grzyb, 2016).

When focusing on the physical place where gender violence occurs, women victims in Portugal reported that these episodes occurred more often at home $(54.4 \%)$ with the partner as the perpetrator (43.9\%). Male victims stated that the violent episodes occurred mostly in public spaces $(40.8 \%)$, indicating that the perpetrator was frequently a stranger $(28.6 \%)$ or a co-worker $(18.4 \%)$ (Dias, Fraga and Barros, 2013).

Regarding the causes which increase the probability of experiencing intimate partner violence among migrant women, a study conducted in Spain concluded that the variables associated with greater vulnerability are ages lower than 18 years, as well as low socioeconomic status, low social support and having a mother who had experienced intimate partner violence (Sanz-Barbero, Rey and Otero-García, 2014). Intimate partner violence was also associated with factors such as being separated and/or divorced, lack of social support and low religious involvement while varying among immigrants from different countries (Vives-Cases et al, 2014). An additional study in Norway showed that immigrant women had lower income, were less likely to use alcohol and had increased likelihood of having an immigrant partner. While no differences were found between ethnic Norwegian and immigrant women concerning intimate partner violence severity, frequency, guilt, shame, or victimization, immigrants were better at predicting physical violence, but had an increased risk of physical injury related to sexual one (Vatnar and Bjørkly, 2010).

Legal, economic and socio-cultural barriers. The risk of violence can increase among immigrant women due to their legal and economic situation and to different barriers to accessing 
information and support services (Martinez-Roman, Vives-Cases and Pérez-Belda, 2017). Intimate partner violence was found to be higher in physically disordered and decaying neighborhoods and in neighborhoods with low educational and economic status levels, high levels of public disorder and crime, and high concentrations of immigrants (Gracia et al., 2015).

In the United Kingdom, inequalities created by culture, gender, class, and race intersect with state immigration and welfare policies, thereby exacerbating structures of patriarchy within minority communities. It is within these contexts that South Asian women with insecure immigration status experience intensified forms and specific patterns of abuse (Anitha, 2011).

Nevertheless, it is important to be aware of the stigmatizing risks that arise from using culture to frame certain forms of violence against women. Applied uncritically, these approaches risk showing immigrants as powerless women victimized by their non-European cultures and is reminiscent of colonial times (Peroni, 2016).

A study conducted in Spain showed that immigrant women are triply affected: by gender violence, by the economic crisis, and by structural violence. In times of economic crisis intimate partner violence-related policies cease to be a priority, resources are reduced as well as staff and the quality of services, making it even more difficult for migrant women (Briones-Vozmediano et al., 2014a).

Violence against women may be considered one of the most extreme forms of gender inequality. Women are further victimized by the worsening of the job market situation and gender discrimination in employment. For instance, migrant women from poor countries increasingly engage in domestic work and care for dependent people, and their access to certain places of work or to a higher level job is very difficult (Legouge and Pfefferkorn 2011).

At the same time, post-migration sources of stress, social isolation and the absence of the ethnic community among Muslims in Italy are interrelated factors, that contribute to gender violence in the post-migration context. In addition to the social and psychological factors, linguistic and cultural barriers also influence women's capability to leave an abusive relationship (Giuliani and Gennari, 2014).

A fundamental issue for migrant women who are victims of gender violence is being able to obtain professional assistance. Nevertheless, for many of them, the availability, accessibility, and quality of psychosocial and health services pose significant barriers. Other reasons for abandoning the help-seeking process involve structural factors such as economic dependence, loss of social support after leaving their country of origin, and limited knowledge about the resources available. In practice, resources allocated to gender-based violence were insufficient to meet battered immigrant women's needs (Briones-Vozmediano et al., 2014b). In Spain, abused immigrant women require a residence permit as a prerequisite for their access to different services and rights. Since frequently these services are not culturally appropriate, women lose confidence in their effectiveness, which may also reflect the lack of appropriate training among professionals on issues related to intimate partner violence and immigration (Briones-Vozmediano et al., 2015).

Social stigmatization, precarious living conditions, and the climate of fear and suspicion generated by increasingly restrictive immigration policies - hinders undocumented immigrants' access to health care rights in the European context (Larchanché, 2012). Thus, injuries due to domestic violence in Germany are a frequent occurrence in emergency departments, which are usually accessible to all. The victims were predominantly female and were attacked by the (ex) partner, although excessive violence with life-threatening or fatal injuries was not usually observed (Gologan et al., 2014). Nevertheless, foreign women living in Spain are especially vulnerable to death from intimate partner violence (Vives-Cases et al., 2008). 
Conflict and war. A special situation to be considered relates to violence against women in situations of conflict or wars. War-related violence in the community of origin created fear, separation and limited access to reproductive health services, exposing Somali women to nonpartner sexual violence or intimate partner violence. The non-disclosure of this violence due to the risk of shame and stigmatization may explain why their violence-related health issue may be overlooked in the health care system in Sweden. Nevertheless, survival strategies shaped by war such as social networks, stoicism, and faith, contain resources for resilience and enhancement of well-being and sexual and reproductive health and rights in receiving countries after migration (Byrskog et al., 2014).

Besides major international and national advances in gendered legislation, the impacts of sexual violence during and beyond conflict situations are profound, although not adequately recognized or considered during the asylum application process, or, in some cases, in localized communities and organizations in the UK (Canning, 2014).

The impact and consequences of violence. Various studies analyze the impact and the consequences of violence for the victims.

For example, internally displaced women in Britain relocate to escape gender violence, although they had not previously intended to migrate. Journeys are focused on trying to minimize disruption either by staying as close as they can while avoiding friends, family, and known locations, or by traveling to a place similar to the one they left. Their primary concern is safety and their journeys are often complex and segmented into multiple stages over time and space (Bowstead, 2015).

Chan (2000) describes situations of hardship and overwork, poverty and deprivation, poor social support and social isolation, unhappy family relationships, gambling husbands and domestic violence, together with language and cultural difficulties that contributed to poor quality of living standards as well as indirectly caused negative psychosocial health outcomes for Chinese mothers in the UK.

Concomitantly, Martínez and Piqueras (2014) relate to the impact of violence on the identity of women, considering how their different trajectories and webs of violence lead to distinct understandings of the violence they have experienced.

Several studies identified the strong connection between violence and mental health among women migrants. Considering that interpersonal violence is frequently found in relations with the partner, the family, and even outside the family, it seriously affects mental health. Thus, social, cultural and economic factors, particularly gender inequality and women's low status in society, are root causes of violence and affect women's mental health directly. In spite of this evidence, most mental health policies and programmes do not systematically include consideration of violence issues (Alvarez-del Arco et al., 2013). Another study focused on the increased risk for poor mental health among Thai women exposed to intimate partner violence in Sweden, constituting an obstacle for their integration (Fernbrant et al., 2014).

Furthermore, mental health services are sorely lacking in low and middle-income countries.

A significant association between gender violence and depression was found in women (aged >18 years) attending general practice in the Netherlands, where half of the abused women were suffering from depression. Therefore, in order to improve recognition of abused women, doctors should ask depressed women if they ever experienced IPV (Prosman et al., 2011). 
Strategies and suggestions for interventions. Some of the studies contain elements to promote the prevention of violence, improve the care for victims as well as how to work with male perpetrators. Thus, for example, an enabling environment promoted by specific gender-related laws and other specific legislative regulations that address IPV in immigrant populations is considered important (Briones Vozmediano, La Parra and Vives-Cases, 2015).

Targeted interventions were also suggested to deal with mental health. Although poor mental health in Thai women in Sweden represented an obstacle for integration, their potential resilience indicated by high social trust and without exposure to social isolation suggested that such aspects must be included in a program designed to facilitate integration (Fernbrant et al., 2014).

It was suggested that professionals should be targeted and trained in the prevention of violence (including gender violence) and mental health, adding this as part of the official curricula of health providers (Garcia-Moreno and Riechler-Rossler, 2013).

Relating to cultural practices, it is estimated that a third of migrant women from countries where Female genital mutilation (FGM) is practiced may have undergone FGM/cutting in their countries of origin and that girls may be at risk. Thus, both policy and targeted interventions to deal with this practice should be planned in advance (Ortensi and Menonna, 2017). Awareness-raising through the combined efforts of families, communities, and governments, together with the development of health education programs addressing the complications derived from FGM, may help to eradicate this practice (Ruiz, Martínez and del Mar Pastor Bravo, 2016).

Considering suicide prevention, it has been demonstrated that population-based intervention program can reverse this trend among ethnic minority groups with high suicide attempt rates across Europe (Aichberger et al., 2015). Another intervention mentioned is working on the basis of overcoming stereotypes through other women's communicative daily life stories (CDLS) conducted with other women from migrant or ethnic minority descent, which can contribute to dismantle existing sexist and racist stereotypes and prevent gender violence (GarcíaYeste, 2014).

A study focusing on interventions for male perpetrators found that the effectiveness of psychological treatment programmes for immigrant men who committed a gender-based violent crime in Spain has increased, as well as the number of participants (Echauri et al., 2013).

When addressing future challenges, Torrubiano-Domínguez and Vives-Cases (2013) indicate that the most important goal for future research is the use of Violence Against Women (VAW) scales validated in different languages, which would help to overcome language barriers. They recommend Putting Women First protocol is an ethical guideline for VAW research, which includes recommendations to ensure the safety of the women involved in studies on this subject.

Further research on the causes of gender-based violence among foreign women, as well as additional strategies involving health services are needed (Vives-Cases et al 2008).

In addition, trafficking should also be addressed since it is a health risk related to gender violence, spanning geographical boundaries and involving multiple sectors, including immigration and law enforcement, labor, social and health services. Thus, interventions must be coordinated between nations and across sectors to promote the protection and recovery of people who are trafficked (Zimmerman, Hossain and Watts, 2011). 


\section{Conclusions}

Migration is often accompanied by an increased risk of gender violence due to a myriad of factors, especially among women who continue to be in a socioeconomic disadvantage in their host country (Fernbrant et al, 2011).

The thematic analysis of the studies dealing with migration and gender violence reviewed in this paper highlighted several important themes, including prevalence of violence against migrant women, the forms and contexts of gender violence, the impact of legal, economic environments and socio-cultural barriers, the influence of conflict and war, the consequences of violence, as well as suggestions for intervention strategies.

It is interesting to note the absence of specific studies relating to femicide among migrant populations in the studies sampled, and it is suggested to raise awareness of and to make this phenomenon visible (Weil 2016b). Concomitantly, studies of gender violence among internally displaced people were also found lacking.

On the other hand, it is necessary to beware and make generalizations when addressing groups of women from a specific geographical area (i.e., Anitha, S., 2011; Byrskog et al., 2014), since there will always be differences and characteristics, which must be considered. The same may occur when the terms ethnicity and culture are juxtaposed, since they often do not have the same meaning.

An additional factor to bear in mind is the importance of the team of investigators, which should always include some from the women's countries of origin, thus facilitating an understanding of the native (emic) perspectives.

Considering the vulnerable situation of women on the move, it is important to reflect on the rise of gender violence and of femicide as a result of complex migration processes.

When targeting immigrant women, it is also essential to consider the post-migration context as a risk factor. For these women, the life in the host country is often characterized by difficulties to access crucial services due to language and socio-cultural barriers, as well as their often unclear legal status and their perception of the host society as a threat (Nudelman et al., 2017).

The types of support and assistance available to migrant women, both from organizations and from the different governmental and European official institutions, should be identified and targeted in order to overcome the different barriers to service access and to enhance culture competency (Rana, 2012). Therefore, it is essential to increase the awareness and sensitivity of migration authorities, including police, legal and healthcare professionals regarding the conflicts and problems experienced by migrants of both genders. This would enable them to offer more significant services, thus contributing to the reduction of gender-based violence and the threat of femicide.

Regarding the limitations of this article, we must indicate the difficulty to identify comprehensive categories of analysis, as observed during the presentation of the results of the thematic analysis. This was a direct consequence of the exclusive use of the abstracts in this preliminary study, also allowing for overlapping categories, which may affect future studies.

Future activities should combine research, prevention, and intervention while considering existing promising practices (Runner et al., 2009) and this is also one of the objectives of our future work. We are in the process of developing a broader study on gender violence and femicide among migrants in Europe, including internally displaced people, while especially focusing on groups in movement (in the process itself). This investigation will encompass other countries included in the Council of Europe, where the issue of internally displaced people is acute, such as Ukraine $(1,653,000)$, Turkey $(1,108,000)$, Azerbaijan $(582,000)$, Georgia $(208,000)$ and Bosnia Herzegovina 
$(98,000)$ (IDMC, 2017). It will also address gender violence among refugees, considering that more than a million people from the Middle East and Africa have entered the EU during the past few years, escaping conflicts and dire conditions in their countries of origin.

One of the objectives of our ongoing work is to apply our research findings to enhance capacity building for professionals as well as in interventions focusing on prevention and care among different groups of migrant women.

\section{Bibliography}

1. Aichberger, M. C., Heredia Montesinos, A., Bromand, Z., Yesil, R., Temur-Erman, S., Rapp, M. A., Heinz, A. and Schouler-Ocak, M., 2015. Suicide attempt rates and intervention effects in women of Turkish origin in Berlin. European Psychiatry, 30(4), pp.480-485.

2. Alvarez-del Arco, D., del Amo, J., Garcia-Pina, R., Garcia-Fulgueiras, A. M., RodriguezArenas, M. A., Ibañez-Rojo, V., Diaz-del Peral, D.,. Jarrin, I., Fernandez-Liria, A., Zunzunegi, M.V., Gartiz-Ortozar V., Mazarrasa L and Llacer, A., 2013. Violence in adulthood and mental health: Gender and immigrant status. Journal of Interpersonal Violence, 28(11), pp.2203-2222.

3. Anitha, S., 2011. Legislating gender inequalities: The nature and patterns of domestic violence experienced by south Asian women with insecure immigration status in the United Kingdom. Violence Against Women, 17(10), pp.1260-1285.

4. Balica, E. and Stöck1, H., 2016. Homicide-suicides in Romania and the role of migration. European Journal of Criminology, 13(4), pp.517-534.

5. Bowstead, J. C., 2015. Forced migration in the United Kingdom: Women's journeys to escape domestic violence. Transactions of the Institute of British Geographers, 40(3), pp.307-320.

6. Briones-Vozmediano, E., Agudelo-Suarez, A. A., Goicolea, I. and Vives-Cases, C., $2014 a$. Economic crisis, immigrant women and changing availability of intimate partner violence services: A qualitative study of professionals' perceptions in Spain. International Journal for Equity in Health, 13(1), pp.1-9.

7. Briones-Vozmediano, E., Goicolea, I., Ortiz-Barreda, G. M., Gil-González, D. and Vives-Cases, C., 2014b. Professionals' perceptions of support resources for battered immigrant women: Chronicle of an anticipated failure. Journal of Interpersonal Violence, 29(6), pp.1006-1027.

8. Briones-Vozmediano, E., La Parra, D. and Vives-Cases, C., 2015. Barriers and facilitators to effective coverage of intimate partner violence services for immigrant women in Spain. Health Expectations, 18(6), pp.2994-3006.

9. Byrskog, U., Olsson, P., Essén, B. and Allvin, M. K., 2014. Violence and reproductive health preceding flight from war: Accounts from Somali born women in Sweden. BMC Public Health, 14(1), p.892. doi: 10.1186/1471-2458-14-892.

10. Cammarella, A., Ferracci, A., Gizzi, N. and Menozzi, F., 2016. Genitorialità, dinamiche relazionali ed esiti evolutivi sui figli di coppie miste coinvolti in situazioni di abuso. Maltrattamento e Abuso all'Infanzia, 18(2), pp.119-138.

11. Canning, V., 2014. International conflict, sexual violence and asylum policy: Merseyside as a case study. Critical Social Policy, 34(1), pp.23-45.

12. Carbajosa, P., Lila, M., Negredo, L. and Pérez, M., 2011. El delito de violencia de género y los penados extranjeros. Madrid: Secretaría General Técnica del Ministerio del Interior.

13. Chan, C., 2000. The quality of life of women of Chinese origin. Health and Social Care in the Community, 8(3), pp.212-222. 
14. Colorado-Yohar, S., Tormo, M. J., Salmerón, D., Dios, S., Ballesta, M. and Navarro, C., 2012. Violence reported by the immigrant population is high as compared with the native population in southeast Spain. Journal of Interpersonal Violence, 27(16), pp.3322-3340.

15. Corradi, C., Marcuello-Servos, C., Boira, S. and Weil, S., 2016. Theories of femicide and their significance for social research. Current Sociology, 64(7), pp. 975-995.

16. Davis, R. C., Erez, E. and Avitabile, N., 2001. Access to Justice for Immigrants Victimized by Crime: The Perspectives of Police and Prosecutors. Criminal Justice Policy Review, 12(3), pp.183-196.

17. Dias, S., Fraga, S. and Barros, H., 2013. Interpersonal violence among immigrants in Portugal. Journal of Immigrant and Minority Health, 15(1), pp.119-124.

18. Echauri, J. A., Fernández-Montalvo, J., Martínez, M. and Azkarate, J. M., 2013. Effectiveness of a treatment programme for immigrants who committed gender-based violence against their partners. [Efectividad de un programa de tratamiento con inmigrantes que ejercen violencia de género contra la pareja] Psicothema, 25(1), pp.49-54.

19. Echeburúa, E. and Fernández-Montalvo, J., 1998. Instrumentos de evaluación de maltratadores. In: E. Echeburúa y P. Corral (dirs.), Manual de violencia familiar Madrid: Pirámide. pp.91-129.

20. Fernández-Montalvo, J., Echauri, J. A., Martínez, M. and Azcárate, J. M., 2011. Gender violence and immigration: Differential profile of national and immigrant male abusers. [Violencia de género e inmigración: Perfil diferencial de hombres maltratadores nacionales e inmigrantes] Behavioral Psychology/Psicologia Conductual, 19(2), pp.439-452.

21. Fernbrant, C., Essén, B., Östergren, P. and Cantor-Graae, E., 2011. Perceived threat of violence and exposure to physical violence against foreign-born women: A Swedish population-based study. Women's Health Issues, 21(3), pp.206-213.

22. Fernbrant, C., Emmelin, M., Essén, B., Östergren, P. -., and Cantor-Graae, E., 2014. Intimate partner violence and poor mental health among Thai women residing in Sweden. Global Health Action, 7(1). Available at: <https://www.ncbi.nlm.nih.gov/pmc/articles/PMC4166544/pdf/GHA7-24991.pdf $>$ [Accessed 17 July 2017].

23. García-Moreno, C. and Riecher-Rössler, A., 2013. Violence against women and mental health. Basel: KARGER.

24. García-Yeste, C., 2014. Overcoming stereotypes through the other women's communicative daily life stories. Qualitative Inquiry, 20(7), pp.923-927.

25. Giuliani, C. and Gennari, M., 2014. Intimate male partner violence and Muslim migration. [Intimate male partner violence: Voci dei migranti musulmani] Maltrattamento e Abuso all'Infanzia, 16(1), pp.101-112.

26. Gologan, R., Aziriu, S., Obertacke, U. and Schreiner, U., 2014. Medical and sociodemographic aspects of domestic violence: Systematic evaluation of patient data from the emergency department of a maximum care hospital. [Medizinische und soziodemographische Aspekte häuslicher Gewalt: Systematische Auswertung von Patientendaten einer Notaufnahme eines Krankenhauses der Maximalversorgung] Unfallchirurg, 117(6), pp.528-532.

27. Gracia, E., Herrero, J., Lila, M. and Fuente, A., 2010. Percepciones y actitudes hacia la violencia de pareja contra la mujer en inmigrantes Latinoamericanos en España. Intervención Psicosocial, 19(2), pp.135-144.

28. Gracia, E., López-Quílez, A., Marco, M., Lladosa, S. and Lila, M., 2015. The spatial epidemiology of intimate partner violence: Do neighborhoods matter? American Journal of Epidemiology, 182(1), pp.58- 66. 
29. Grzyb, M. A., 2016. An explanation of honor-related killings of women in Europe through Bourdieu's concept of symbolic violence and masculine domination. Current Sociology, 64(7), pp.1036-1053.

30. Hazen, A. L. and Soriano, F. I., 2007. Experiences with intimate partner violence among Latina women. Violence Against Women, 13(6), pp.562-582.

31. Ingram, E. M., 2007. A comparison of help seeking between Latino and non-Latino victims of intimate partner violence. Violence Against Women, 13(2), pp.159-171.

32. Larchanché, S., 2012. Intangible obstacles: Health implications of stigmatization, structural violence, and fear among undocumented immigrants in France. Social Science and Medicine, 74(6), pp.858-863.

33. Legouge, P. and Pfefferkorn, R., 2011. Inequalities between men and women: Advances and hurdles. [Inégalités hommes - Femmes: Avancées et obstacles]. Pensee, 367, pp.95-103.

34. Martínez, P. R. and Piqueras, C. C., 2014. Analysis of judicial decisions on partner violence among migrant and Spanish population in Almeria and Murcia (2005-2010). [Analisis de resoluciones judiciales sobre violencia en la pareja en la población migrante y española en Almería y Murcia (2005-2010)] Migraciones, 2014(35), pp.99-127.

35. Martinez-Roman, M., Vives-Cases, C. and Pérez-Belda, C., 2017. Immigrant women suffering from IPV in Spain: The perspectives of experienced social workers. Affilia - Journal of Women and Social Work, 32(2), pp.202-216.

36. Nudelman, A., Boira, S., Tsomaia, T., Balica, E. y Tabagua, S., 2017. "Hearing their voices": exploring femicide among migrants and culture minorities. Qualitative Sociology Review, 10(3), pp.49-68.

37. Ortensi, L.E. and Menonna, A., 2017. Migrating with special needs? Projections of flows of migrant women with female genital Mutilation/Cutting toward Europe 2016-2030. European Journal of Population, 33(4), pp. 559-583. |

38. Peroni, L., 2016. Violence against migrant women: The Istanbul convention through a postcolonial feminist lens. Feminist Legal Studies, 24(1), pp.49-67.

39. Prosman, G., Jansen, S. J. C., Lo Fo Wong, S. H. and Lagro-Janssen, A. L. M., 2011. Prevalence of intimate partner violence among migrant and native women attending general practice and the association between intimate partner violence and depression. Family Practice, 28(3), pp.267271.

40. Raj, A. and Silverman, J., 2002. Violence Against Immigrant Women: The Roles of Culture, Context, and Legal Immigrant Status on Intimate Partner Violence. Violence Against Women, 8(3), pp.367-398.

41. Rabito-Alcón, M. F., Puente-García, R., Cámara-Blanco, L., De Frutos-Moneo, E., García-Jorge, S. and Correas-Lauffer, J., 2013. Differential perception of gender violence by Romanian immigrants resident in the metropolitan area of Madrid. [Percepción diferencial de la violencia de género por las inmigrantes rumanas residentes en una zona de la corona metropolitana de Madrid] Semergen, 39(5), pp.247-251.

42. Rana, S., 2012. Addressing Domestic Violence in Immigrant Communities: Critical Issues for Culturally Competent Services. Harrisburg, PA: VAWnet, a project of the National Resource Center on Domestic Violence. Available at: https://vawnet.org/sites/default/files/materials/files/2016-09/AR_DVImmigrantComm.pdf [Accessed 17 July 2017].

43. Ruiz, I. J., Martínez, P. A. and del Mar Pastor Bravo, M., 2016. Key points for abolishing female genital mutilation from the perspective of the men involved. Midwifery, 34, pp.30-35. 
44. Runner, M., Yoshihama, M. and Novick, S., 2009. Intimate Partner Violence in Immigrant and Refugee Communities: Challenges, Promising Practices and Recommendations. Princeton, NJ: Robert Wood Johnson Foundation and Futures Without Violence.

45. Sanz-Barbero, B., Rey, L. and Otero-García, L., 2014. Health status and intimate partner violence. [Estado de salud y violencia contra la mujer en la pareja] Gaceta Sanitaria, 28(2), pp.102-108.

46. Sela-Shayovitz, R., 2010. The role of ethnicity and context: Intimate femicide rates among social groups in Israeli society. Violence Against Women, 16(12), pp.1424-1436.

47. Torrubiano-Domínguez, J. and Vives-Cases, C., 2013. Application of the putting women first protocol in a study on violence against immigrant women in Spain. Gaceta Sanitaria, 27(6), pp.555-557.

48. Vatnar, S. K. B. and Bjørkly, S., 2010. An interactional perspective on the relationship of immigration to intimate partner violence in a representative sample of help-seeking women. Journal of Interpersonal Violence, 25(10), pp.1815-1835.

49. Vives-Cases, C., Álvarez-Dardet, C., Torrubiano-Domínguez, J. and Gil-González, D., 2008. Mortality due to intimate partner violence in foreign women living in Spain [1999-2006]. [Mortalidad por violencia del compañero íntimo en mujeres extranjeras residentes en España (1999-2006)] Gaceta Sanitaria, 22(3), pp.232-235.

50. Vives-Cases, C., Torrubiano-Domínguez, J., Gil-González, La Parra, D., Aqudelo-Suárez, A. A., Davó, M. C., Perez-Belda, M.C. and Martínez-Román, M. A., 2014. Social and immigration factors in intimate partner violence among Ecuadorians, Moroccans and Romanians living in Spain. European Journal of Public Health, 24(4), pp.605-612.

51. Weil, S., 2016a. Failed femicides among migrant survivors. Qualitative Sociology Review, 12(4), pp.6-21.

52. Weil, S., 2016b. Making femicide visible. Current Sociology, 64(7), pp.1124-1137.

53. Zimmerman, C., Hossain, M. and Watts, C., 2011. Human trafficking and health: A conceptual model to inform policy, intervention and research. Social Science and Medicine, 73(2), pp.327335.

54. ***European Union Agency for Fundamental Rights, 2014. Violence against women: An EUwide survey. Luxembourg: Publications Office of the European Union.

55. ***Eurostat, 2016. Migration and migrant population statistics explained. Available at: <http://ec.europa.eu/eurostat/statistics> [Accessed 15 July 2017].

56. ***IDMC - Internal Displacement Monitoring Centre. 2017. GRID 2017 - Mini Global Report on Internal Displacement. Geneva: IDMC. 